Benha Veterinary Medical Journal 39 (2020) 10-14

Benha Veterinary Medical Journal
$\begin{gathered}\text { Official Journal Issued by } \\ \text { Fecterly of } \\ \text { Veterinary Medicine }\end{gathered}$
Journal homepage: https://bvmj.journals.ekb.eg/

Original Paper

\title{
Bacterial hazards of ready to eat fish products
}

Faten Hassanien', Mohamed Hassan', Nahla Abou ELRoos ${ }^{2}$, Eslam El-Gazzar ${ }^{2}$

${ }^{l}$ Food Hygiene and Control Department, Faculty of Veterinary Medicine, Benha University

${ }^{2}$ Food Hygiene Department, Animal Health Research Institute, Shebin Al Kom Branch

\begin{tabular}{|c|c|}
\hline ARTICLE INFO & ABSTRACT \\
\hline $\begin{array}{l}\text { Keywords } \\
\text { Bacterial hazards } \\
\text { Fried tilapia } \\
\text { Grilled tilapia } \\
\text { Salted Sardine } \\
\text { Smoked Herring } \\
\text { Received } 08 / 03 / 2020 \\
\text { Accepted } 06 / 10 / 2020 \\
\text { Available On-Line } \\
\text { 20/01/2021 }\end{array}$ & $\begin{array}{l}\text { The aim of this study was to evaluate the bacterial quality of the examined ready to eat (RTE) } \\
\text { fish product samples through isolation and identification of Enteropathogenic E. coli, } \\
\text { Coagulase +ve S. aureus and Vibrio parahaemolyticus. A total of one hundred random samples } \\
\text { of RTE fish products represented by fried Nile tilapia, grilled tilapia, smoked herring and salted } \\
\text { sardine ( } 25 \text { of each) were collected from different fish markets and restaurants in Menofia } \\
\text { governorate, Egypt. The incidence of Enteropathogenic Escherichia coli (E.coli) were } 24 \% \text {, } \\
32 \%, 36 \% \text { and } 50 \% \text { in the examined samples of fried tilapia, grilled tilapia, smoked herring } \\
\text { and salted sardine, respectively. While, Coagulase +ve Staphylococcus aureus (S. aureus) was } \\
\text { detected in } 32 \%, 44 \%, 52 \% \text { and } 72 \% \text { of the examined samples of fried tilapia, grilled tilapia, } \\
\text { smoked Herring and salted Sardine, respectively. Furthermore, Vibrio parahaemolyticus (V. } \\
\text { parahaemolyticus ) was isolated only from } 20 \% \text { and } 36 \% \text { of the examined samples of smoked } \\
\text { herring and salted sardine, respectively. In conclusion, bacterial examination of RTE fish } \\
\text { products is a sensitive indicator verifying the quality and good hygienic status of RTE fish } \\
\text { products }\end{array}$ \\
\hline
\end{tabular}

\section{INTRODUCTION}

Ready to eat (RTE) fish products is a perfect food stuff which is up to standards of national nourishment, in addition it is a source of healthy and good digestible materials i.e. highquality protein, minerals, vitamins, high amino acids content and high proportion of unsaturated fatty acids (Toth et al., 2012). Nevertheless, there is major evidence that RTE fish products are on the list of foods associated with outbreaks of food borne diseases, where raw or undercooked fish acts as a source to Enteropathogenic E.coli, S. aureus and V. parahaemolyticus (Ahmad et al., 2017). Contamination sources of RTE fish products could come from several ways such as contact with food handlers and asymptomatic carriers suffering from infected skin lesions, poor hand and fingernail hygiene as, the workers during preparation process may touch cooked RTE fish products that are usually eaten without further cooking or re-heating. Also, contacting with inadequate unclean utensils or serving plates, contaminated preparation surfaces, poor sanitation in kitchens, insects, rodents and other animals all can cause this illness along with temperature abuse of food. So, it is necessary to use HACCP system in restaurants for prevention of food borne diseases (Nichols et al., 2002). E. coli has been considered as an indicator to sewage pollution and reported as opportunistic pathogen in fish (Fredrick et al., 2015). Some types of E. coli can produce Shiga toxins (stx), these are called Shiga toxigenic E. coli (STEC). Enterohemorrhagic E. coli $\mathrm{O}_{157}: \mathrm{H}_{7}$ induces illness secondary to its production of stx that causes a range of gastrointestinal and enterohemorrhagic disease start from watery diarrhea to hemorrhagic colitis and hemolytic uremic syndrome (HUS) (Erickson et al., 2019). S. aureus is a true food poisoning organism as it produces heat stable Staphylococcal enterotoxins (SEs) when allowed to grow in foods. Even if the food is heated before eating, the poison in the food will cause illness although the heat has killed the bacterial cells (Soriano et al., 2012). Staphylococcal food poisoning is associated with nausea, vomiting, abdominal cramps and diarrhea, which are the most common symptoms appear 3$8 \mathrm{hrs}$ after ingestion (Pinchuk et al., 2010). Vibrio is among the most common surface organisms in surface waters of the world and they considered as part of the indigenous microflora of the marine environment (Hasan et al., 2010). Many halophilic $V$. species such as $V$. parahaemolyticus have been implicated in human enteric infection. Clinical symptoms of $V$. parahaemolyticus poisoning are acute dysentery and abdominal pain, accompanied by diarrhea, nausea, vomiting, fever, chills and water like stools (Guillod et al., 2019). It is better to consume RTE fish products consumed immediately, otherwise they should be hold hot foods at or above $60{ }^{\circ} \mathrm{C}$ or cool them quickly in the refrigerator to $4.4^{\circ} \mathrm{C}$ for rapid cooling because, bacteria can grow rapidly in the danger zone temperatures between $5{ }^{\circ} \mathrm{C}$ and $60{ }^{\circ} \mathrm{C}$. So, keep hot foods "hot" and cold foods "cold" (Shale et al., 2005).

\section{MATERIAL AND METHODS}

2.1. Collection of samples

A total of one hundred random samples of RTE fish products represented by fried tilapia, grilled tilapia, smoked herring and

\footnotetext{
* Corresponding author:_Eslam El-Gazzar Food Hygiene Dept. , Animal Health Research Institute, Shebin Al kom Branch
} 
salted sardine ( 25 of each) were collected from different fish markets and restaurants in Menofia governorate, Egypt. Collected samples were separately kept in sterile plastic bags and preserved in an ice box, transferred to the laboratory under aseptic conditions without any delay and suspected to bacteriological examination for detection of food poisoning bacteria in examined samples and their suitability for human consumption.

\subsection{Preparation of samples According to ICMSF} (1996)

25 grams of the sample, $225 \mathrm{ml}$ of sterile peptone water were added and thoroughly mixed using sterile blender for 1.5 minutes to provide a homogenate 1:10 form which tenth fold decimal dilutions were prepared.

\subsection{Screening of pathogenic E. coli}

From the original dilution, one $\mathrm{ml}$ was inoculated into MacConkey broth tubes supplemented with inverted Durham's tubes. Inoculated tubes were incubated at $37{ }^{\circ} \mathrm{C}$ for 24 hours. Suspected colonies were metallic green in color.

2.3.1. Morphological examination, motility test and biochemical identification

The Culture characteristics, motility and all presumptive biochemical identification were done as described by MacFaddin (2000).

2.3.2. Serodiagnosis of E. coli According to Kok et al. (1996)

A rapid diagnostic E. coli antisera sets (Denka Seiken Co., Japan) were used for diagnosis of the Enteropathogenic types.

2.4. Determination of $S$. aureus

From previously prepared dilutions $0.1 \mathrm{ml}$ was spread over duplicated pates of Baird Parker agar plate. The inoculated and control plates were incubated at $37{ }^{\circ} \mathrm{C}$ for $48 \mathrm{hrs}$. Suspected colonies of $S$. aureus appear as black, shiny, circular, smooth and convex with narrow white margin. All the procedures followed FDA, (2001)

2.4.1. Morphological examination, Motility test and Biochemical identification

2.4.2. Detection and typing of enterotoxin

Reverse Passive Latex Agglutination technique "RPLA" kits were used for the detection of staphylococcal enterotoxins A, B, C and D (SET-RPLA, Denka Sekeu LTD, Japan) following MacFaddin (2000).

\subsection{Detection of $V$. parahaemolyticus}

As described by ISO (2017) $25 \mathrm{~g}$ of each sample were homogenized with $225 \mathrm{ml}$ of sterile alkaline peptone water (3\% $\mathrm{NaCl}$ and $\mathrm{pH} 8$ ) and incubated over night at $37{ }^{\circ} \mathrm{C}$. Then streaked onto Thiosulfate citrate bile and sucrose agar and incubated at $37{ }^{\circ} \mathrm{C}$ for 24 hrs. Typical colony of $V$. parahaemolyticus appeared as smooth and green (sucrose negative)

\section{RESULTS}

\subsection{Enteropathogenic E. coli}

The results in table $(1 \& 2)$ revealed that, 37 isolates of $E$. coli were isolated from examined samples represented as: $6(24 \%)$ from fried tilapia with serotypes $\mathrm{O} 44: \mathrm{H} 18(4 \%)$ O111:H2 (4\%), O119:H6 (4\%), O121:H7 (8\%) \& O128:H2 $(4 \%) ; 8(32 \%)$ from grilled tilapia with serotypes O26:H11 (4\%), O111:H2 (8\%), O114:H4 (4\%), O121:H7 (4\%), O124 (4\%) \& O126:H21 (8\%); 9 (36\%) from smoked herring with serotypes O44:H18 (4\%), O91:H21 (12\%), O111:H2 (4\%), O114:H4 (4\%), O124 (4\%), O128:H2 (8\%) \& O171 (4\%) and $14(50 \%)$ from salted sardine with serotypes O26:H11 (4\%), O55:H7 (4\%), O91:H21 (4\%), O111:H2 (8\%), O121:H7 (4\%), O124 (8\%), O126:H21 (4\%) \& O128: H2 $(12 \%)$.

Table 1 Incidence of Enteropathogenic E. coli in the examined samples of ready to eat fish products and their acceptability $(\mathrm{n}=25)$.

\begin{tabular}{|c|c|c|c|c|c|c|c|}
\hline \multirow[t]{3}{*}{ Fish products } & \multicolumn{2}{|c|}{ E. coli incidence } & \multicolumn{5}{|c|}{ Acceptability * } \\
\hline & \multirow{2}{*}{ No. of +ve samples } & \multirow{2}{*}{$\%$ of +ve samples } & \multirow[t]{2}{*}{ E. coli count $/ 25 \mathrm{~g}^{*}$} & \multicolumn{2}{|c|}{ Accepted samples } & \multicolumn{2}{|c|}{ Unaccepted samples } \\
\hline & & & & No. & $\%$ & No. & $\%$ \\
\hline Fried $O$. niloticus & 6 & 24 & Free & 19 & 76 & 6 & 24 \\
\hline Grilled $O$. niloticus & 8 & 32 & Free & 17 & 68 & 8 & 32 \\
\hline Smoked Herring & 9 & 36 & Free & 16 & 64 & 9 & 36 \\
\hline Salted Sardine & 14 & 56 & Free & 11 & 44 & 14 & 56 \\
\hline Total & 37 & 37 & & 63 & 63 & 37 & 37 \\
\hline
\end{tabular}

"Egyptian Organization for Standardization "EOS" (2005). No 1725-2/2005 for salted fish, No 288/2005 for smoked fish and No 3495/2005 for fish products breaded or in batter.

\begin{tabular}{|c|c|c|c|c|c|c|c|c|c|}
\hline \multirow{2}{*}{ E. coli strains } & \multicolumn{2}{|c|}{ Fried O. niloticus } & \multicolumn{2}{|c|}{ Grilled $O$. niloticus } & \multicolumn{2}{|c|}{ Smoked Herring } & \multicolumn{2}{|c|}{ Salted Sardine } & \multirow{2}{*}{$\begin{array}{c}\text { Strain } \\
\text { Characteristics }\end{array}$} \\
\hline & No. & $\%$ & No. & $\%$ & No. & $\%$ & No. & $\%$ & \\
\hline $\mathrm{O}_{26}: \mathrm{H}_{11}$ & - & - & 1 & 4 & - & - & 3 & 12 & EHEC \\
\hline $\mathrm{O}_{44}: \mathrm{H}_{18}$ & 1 & 4 & - & - & 1 & 4 & - & - & EPEC \\
\hline $\mathrm{O}_{55}: \mathrm{H}_{7}$ & - & - & - & - & - & - & 1 & 4 & EHEC \\
\hline $\mathrm{O}_{91}: \mathrm{H}_{21}$ & - & - & - & - & 3 & 12 & 1 & 4 & EHEC \\
\hline $\mathrm{O}_{111}: \mathrm{H}_{2}$ & 1 & 4 & 2 & 8 & 1 & 4 & 2 & 8 & EHEC \\
\hline $\mathrm{O}_{114}: \mathrm{H}_{4}$ & - & - & 1 & 4 & 1 & 4 & - & - & EPEC \\
\hline $\mathrm{O}_{119}: \mathrm{H}_{6}$ & 1 & 4 & - & - & - & - & - & - & EPEC \\
\hline $\mathrm{O}_{121}: \mathrm{H}_{7}$ & 2 & 8 & 1 & 4 & - & - & 1 & 4 & EHEC \\
\hline $\mathrm{O}_{124}$ & - & - & 1 & 4 & 1 & 4 & 2 & 8 & EIEC \\
\hline $\mathrm{O}_{126}: \mathrm{H}_{21}$ & - & - & 2 & 8 & - & - & 1 & 4 & ETEC \\
\hline $\mathrm{O}_{128}: \mathrm{H}_{2}$ & 1 & 4 & - & - & 2 & 8 & 3 & 12 & ETEC \\
\hline $\mathrm{O}_{171}$ & - & - & - & - & 1 & 4 & - & - & EPEC \\
\hline Total (100) & 6 & 24 & 8 & 32 & 10 & 36 & 14 & 48 & \\
\hline
\end{tabular}


The acceptability of the examined samples was shown in table (1) as 63 accepted samples represented as $19(76 \%), 17$ $(68 \%), 16(64 \%)$ and $11(44 \%)$ from fried tilapia, grilled tilapia, smoked herring and salted sardine, respectively. While 37 unaccepted samples represented as $6(24 \%), 8$ (32\%), $9(36 \%)$ and $14(56 \%)$ from fried tilapia, grilled tilapia, smoked herring and salted sardine, respectively.

\subsection{Coagulase positive $S$. aureus}

The results in tables $(3 \& 4)$ revealed that 48 isolates of coagulase positive $S$. aureus were isolated from examined samples represented as $8(32 \%)$ from fried tilapia with enterotoxin C (4\%); 11 (44\%) from grilled tilapia with enterotoxin A (4\%); 13 (52\%) from smoked herring with enterotoxins A\& B (4\%) and A \& C (4\%) and $16(72 \%)$ from salted sardine with enterotoxins A $(8 \%), \mathrm{D}(4 \%)$ and B $\& \mathrm{D}(4 \%)$.

The acceptability of the examined samples was shown in table (3) as 42 accepted samples represented as 14(56\%), 12 $(48 \%), 9(36 \%)$ and $7(28 \%)$ from fried tilapia, grilled tilapia, smoked herring and salted sardine, respectively; while 58 unaccepted samples represented as 11 (44\%), 13 (52\%), $16(64 \%)$ and 18 (72\%) from fried tilapia,, grilled tilapia,, smoked herring and salted sardine, respectively.

\subsection{V. parahaemolyticus}

The results in table (5) revealed that 14 isolates of $V$. parahaemolyticus species were isolated from examined samples represented as 5 (20\%) from smoked Herring, 9 $(36 \%)$ from salted Sardine, while fried tilapia, and grilled tilapia, were free from vibrio $(0 \%)$. The acceptability of the examined samples represented as 90 accepted samples represented as $25(100 \%), 25(100 \%), 22(88 \%)$ and 18 $(72 \%)$ from fried tilapia,, grilled tilapia,, smoked herring and salted Sardine, respectively; while 10 unaccepted samples represented as $3(12 \%)$ from smoked Herring and 7 (28\%) from salted Sardine. This according to Egyptian Organization for Standardization "EOS" (2005) (No 1725$2 / 2005$ for salted fish, No 288/2005 for smoked fish and No $3495 / 2005$ for fish products breaded or in batter).

Table 3 Incidence of coagulase +ve $S$. aureus in the examined samples of ready to eat fish products and their acceptability $(\mathrm{n}=25)$.

\begin{tabular}{|c|c|c|c|c|c|c|c|}
\hline \multirow[t]{3}{*}{ Fish products } & \multicolumn{2}{|c|}{ S. aureus incidence } & \multirow{3}{*}{ S. aureus count $/ 25 \mathrm{~g}$} & \multicolumn{4}{|c|}{ Acceptability* } \\
\hline & \multirow[t]{2}{*}{ No. of +ve samples } & \multirow[t]{2}{*}{$\%$ of +ve samples } & & \multicolumn{2}{|c|}{ Accepted samples } & \multicolumn{2}{|c|}{ Unaccepted samples } \\
\hline & & & & No. & $\%$ & No. & $\%$ \\
\hline Fried $O$. niloticus & 8 & 32 & Free & 14 & 56 & 11 & 44 \\
\hline Grilled $O$. niloticus & 11 & 44 & Free & 12 & 48 & 13 & 52 \\
\hline Smoked Herring & 13 & 52 & Free & 9 & 36 & 16 & 64 \\
\hline Salted Sardine & 16 & 72 & Free & 7 & 28 & 18 & 72 \\
\hline Total & 48 & 48 & & 42 & 42 & 58 & 58 \\
\hline
\end{tabular}

* Egyptian Organization for Standardization "EOS" (2005). No 1725-2/2005 for salted fish, No 288/2005 for smoked fish and No 3495/2005 for fish products breaded or in batter.

\begin{tabular}{|c|c|c|c|c|c|c|c|c|c|c|}
\hline \multirow[t]{2}{*}{ Enterotoxin } & \multicolumn{2}{|c|}{ Fried $O$. niloticus } & \multicolumn{2}{|c|}{ Grilled O. niloticus } & \multicolumn{2}{|c|}{ Smoked Herring } & \multicolumn{2}{|c|}{ Salted Sardine } & \multicolumn{2}{|c|}{$\begin{array}{l}\text { Total } \\
(100)\end{array}$} \\
\hline & No. & $\%$ & No. & $\%$ & No. & $\%$ & No. & $\%$ & No. & $\%$ \\
\hline $\mathrm{A}$ & 0 & 0 & 1 & 4 & 0 & 0 & 2 & 8 & 3 & 3 \\
\hline $\mathrm{C}$ & 1 & 4 & 0 & 0 & 0 & 0 & 0 & 0 & 1 & 1 \\
\hline D & 0 & 0 & 0 & 0 & 0 & 0 & 1 & 4 & 1 & 1 \\
\hline$A \& B$ & 0 & 0 & 0 & 0 & 1 & 4 & 0 & 0 & 1 & 1 \\
\hline$A \& C$ & 0 & 0 & 0 & 0 & 1 & 4 & 0 & 0 & 1 & 1 \\
\hline B \& D & 0 & 0 & 0 & 0 & 0 & 0 & 1 & 4 & 1 & 1 \\
\hline Total & 1 & 4 & 1 & 4 & 2 & 8 & 4 & 16 & 8 & 8 \\
\hline
\end{tabular}

Table 5 Incidence of V. parahaemolyticus in the examined samples of ready to eat fish products and their acceptability $(\mathrm{n}=25)$.

\begin{tabular}{|c|c|c|c|c|c|c|c|}
\hline \multirow{3}{*}{ Fish products } & \multicolumn{2}{|c|}{ V. parahaemolyticus incidence } & \multirow{3}{*}{ V. parahaemolyticus count $/ 25 \mathrm{~g}^{*}$} & \multicolumn{4}{|c|}{ Acceptability* } \\
\hline & \multirow[t]{2}{*}{ No. of +ve samples } & \multirow[t]{2}{*}{$\%$ of +ve samples } & & \multicolumn{2}{|c|}{ Accepted samples } & \multicolumn{2}{|c|}{ Unaccepted samples } \\
\hline & & & & No. & $\%$ & No. & $\%$ \\
\hline Fried $O$. niloticus & 8 & 32 & Free & 25 & 100 & 0 & 0 \\
\hline Grilled $O$. niloticus & 11 & 44 & Free & 25 & 100 & 0 & 0 \\
\hline Smoked Herring & 13 & 52 & Free & 22 & 88 & 3 & 12 \\
\hline Salted Sardine & 16 & 72 & Free & 18 & 72 & 7 & 28 \\
\hline Total & 48 & 48 & & 90 & 90 & 10 & 10 \\
\hline
\end{tabular}

\section{DISUCSSION}

Contamination of fish with organisms of public health significant remains as a major global concern that affects the consumer. Therefore, a serious attention has to be given to RTE fish products that act as a vector for human pathogenic bacteria (Jacxsens et al., 2009). Therefore, the present study was carried out on fried tilapia, grilled tilapia, smoked herring and salted sardine (25 of each), collected from Menofia governorate, Egypt to evaluate the bacterial hazards for them.
The incidence of Enteropathogenic E. coli in the examined samples and their acceptability was showed that $E$. coli was isolated from 37 samples represented as: $6(24 \%)$ fried $O$. niloticus, 8 (32\%) grilled O. niloticus, 9 (36\%) smoked herring and $14(50 \%)$ salted sardine. The acceptability of the examined samples were 63 accepted samples represented as $19(76 \%), 17(68 \%), 16(64 \%)$ and $11(44 \%)$ from fried $O$. niloticus, grilled $O$. niloticus, smoked herring and salted sardine, respectively; while 37 unaccepted represented as 6 (24\%), 8(32\%), $9(36 \%)$ and $14(56 \%)$ from fried $O$. niloticus, grilled $O$. niloticus, smoked herring and salted 
sardine, respectively. This according to Egyptian Organization for Standardization "EOS" (2005).

Serotyping of E. coli serotypes isolated from the examined samples of ready to eat fish products and results showed that fried $O$. niloticus with serotypes O44:H18 (4\%), O111:H2 (4\%), O119:H6 (4\%), O121:H7 (8\%) \& O128:H2 (4\%); grilled $O$. niloticus with serotypes $\mathrm{O} 26: \mathrm{H} 11(4 \%), \mathrm{O} 111: \mathrm{H} 2$ (8\%), O114:H4 (4\%), O121:H7 (4\%), O124 (4\%) \& O126:H21 (8\%); smoked herring with serotypes O44:H18 (4\%), O91:H21 (12\%), O111:H2 (4\%), O114:H4 (4\%), $\mathrm{O} 124(4 \%), \mathrm{O} 128: \mathrm{H} 2(8 \%) \& \mathrm{O} 171(4 \%)$ and salted sardine with serotypes $\mathrm{O} 26: \mathrm{H} 11(4 \%), \mathrm{O} 55: \mathrm{H} 7(4 \%), \mathrm{O} 91: \mathrm{H} 21$ (4\%), O111:H2 (8\%), O121:H7 (4\%), O124 (8\%), O126:H21 (4\%) \& O128: H2 (12\%). The obtained results are being higher than those obtained by Ramadan (2009) who isolated E. coli from $20 \%$ of RTE samples of tilapia. The current results are being lower than those recorded by Hassan (2013) isolated E. coli from $57.10 \%$ of RTE samples of tilapia. These results came in accordance with those obtained by Atanassova et al. (2014) isolated E. coli from $56 \%$ of salted fish samples. According, the increased incidence of $E$. coli in the examined samples may be due to mishandling during production and distribution, leading to gastroenteritis characterized by vomiting, abdominal pain, paralysis and low fever (Olaleye and Abegunde, 2015).

$S$. aureus is considered a major problem worldwide as it can be found in respiratory passages, skin and superficial wounds of man. Thus, Contamination with $S$. aureus is important risk index in evaluation of safety and hygienic quality of food (Jyhshiun et al., 2009). The results of the incidence of coagulase +ve $S$. aureus in the examined samples and their acceptability revealed that coagulase $+v e$ $S$. aureus was isolated from 48 samples represented as $8(32 \%)$ fried tilapia, $11(44 \%)$ grilled tilapia, 13(52\%) smoked herring and $16(72 \%)$ salted sardine. Acceptability of the examined samples was 42 accepted samples represented as $14(56 \%), 12(48 \%), 9(36 \%)$ and $7(28 \%)$ from fried tilapia,, grilled tilapia,, smoked herring and salted sardine, respectively; while 58 unaccepted samples represented as $11(44 \%), 13(52 \%), 16(64 \%)$ and 18 (72\%) from fried tilapia,, grilled tilapia, smoked herring and salted sardine, respectively. This according to Egyptian Organization for Standardization "EOS" (2005).

The results of the incidence of enterotoxins producing $S$. aureus isolated from the examined samples of ready to eat fish products and results showed that fried tilapia, with enterotoxin C (4\%); grilled tilapia, with enterotoxin A (4\%), moked herring with enterotoxins A\&B (4\%) and A\&C (4\%) and salted sardine with enterotoxins A $(8 \%), \mathrm{D}(4 \%)$ and $\mathrm{B} \& \mathrm{D}(4 \%)$. The obtained results are being higher than those obtained by Vazquez-Sanchez (2012) isolated S. aureus from $27 \%$ of salted fish and $26 \%$ of smoked fish samples. The current results are being lower than those recorded by Grigoryan et al. (2010) detected S. aureus in $74 \%$ of the analyzed samples of smoked fish. Nearly similar results were recorded by Subramanian (2007).

The presence of specific human pathogenic vibrio species can serve as an indicator of public health safety of food destined for human consumption. Vibriosis is characterized by diarrhea, primary septicemia and wound infections (Shimohata and Takahashi, 2010). The results of the incidence of $V$. parahaemolyticus in the examined samples and their acceptability revealed that $V$. species were isolated from 14 samples represented as $5(20 \%)$ smoked Herring and $9(36 \%)$ salted Sardine, and failed to be detected in grilled and fried tilapia. Acceptability of the examined samples represented as 90 accepted samples represented as 25 (100\%), $25(100 \%), 22(88 \%)$ and $18(72 \%)$ from fried tilapia, grilled tilapia, smoked Herring and salted Sardine, respectively. While 10 unaccepted represented as $3(12 \%)$ smoked Herring and 7 (28\%) salted Sardine, this according to Egyptian Organization for Standardization "EOS" (2005). The obtained results are being higher than those obtained by Vigano et al. (2007) couldn't isolate $V$. parahaemolyticus from the examined samples of fried sea foods. The current results are being lower than those recorded by Abd Allah (2010) isolated vibrio organisms from $20 \%$ of the examined samples of sardine. These results were agreed with those reported by Al-Sunaiher et al. (2010) detected $V$. parahaemolyticus in $16.8 \%$ of the total examined samples of RTE fish. The factors associated with post heat treatment contamination of RTE fish products may be attributed to direct contact with poor personal hygiene food handlers, no pre-employment and routine medical examination for $S$. aureus, contaminated utensils or serving plates, contamination of preparation surfaces, poor sanitation in kitchens and improper storage of cooked food. So, to avoid the post heat treatment contamination of RTE fish products we should protect cooked sea food from insects, rodents and other animals, application of HACCP system in all fish restaurants to ensure food safety and keep kitchens and foodserving areas clean and sanitized Center for Health Protection "CHP" (2010). Cross- contamination between raw sea food containing pathogens and cooked RTE fish products should be avoided as possible as we can by separating from raw food, avoid preparing RTE fish products dishes and raw foods at the same time, prevent cross-contamination between fish tank water and RTE fish products and cooked sea food should be stored in cleaned sealed containers to protect them from contamination Donald et al. (2001). Heat treatment process of fish considers one of the most suitable methods to contain the risk of food born disease illness by decreasing and preventing the growth and the presence of pathogenic microorganism such as E.coli, $S$. aureus and $V$. parahaemolyticus in RTE fish products. So, it is be recommended to using the following heat treatments processes to get the best results in reaching to RTE fish products free from pathogenic microorganism as possible as we can: frying $190{ }^{\circ} \mathrm{C} / 10 \mathrm{~min}$, roasting for $30 \mathrm{~min}$. and in oven $120^{\circ} \mathrm{C} / 35 \mathrm{~min}$ or $150{ }^{\circ} \mathrm{C} / 45 \mathrm{~min}$ in microwave Lahmer et al. (2017).

\section{CONCULOSIONS}

The current study allow to conclude that the examined samples of fried tilapia, grilled tilapia, smoked herring and salted sardine proved to be contaminated with various microorganisms such as (Enteropathogenic E. coli, coagulase +ve $S$. aureus and $V$. parahaemolyticus).

Therefore, RTE fish products constitute, at times, a public health hazard. Consequently, illness can be prevented by proper cooking, avoiding post-cooking contamination and good hygienic practices.

\section{REFERENCES}

1. Abd Allah, M.S. 2010. Microbiological risk assessment in raw and ready-to-eat fish at Dakahlia province. Thesis, Doctor of Philosophy of Veterinary Medicine, (Food Hygiene \& Control), University of Mansoura, Egypt. 
2. Ahmad, A., Faja, M.O., Abd Sharad, A., Usup, G., 2017. Isolation, identification and distribution of potentially pathogenic bacteria associated with selected water bodies and fish organs in different locations in Peninsular Malaysia. International Journal of Advanced Scientific and Technical Research 7(1), 323-343.

3. Al-Sunaiher, E.A., Abdelnasser, S.S.I., Al-Salamah, A.A., 2010. Association of Vibrio Species with Disease Incidence in Some Fishes in the Kingdom of Saudi Arabia. World Applied Sciences Journal 8(5), 653-660

4. Atanassova, M.R. Chapeia, M.J., Maestu, A.G., 2014 Microbiological Quality of Ready-to-Eat Pickled Fish Products. Journal Aquatic Food Product Technology 23, 498510.

5. CHP (Center for Health Protection), 2011. Review of Staphylococcal Food Poisoning in Hong Kong, Scientific Committee on Enteric Infections and Food borne Diseases,1-18. https://www.chp.gov.hk/files/pdf/review_of_staphylococcal_f ood_poisoning_in_hong_kong_r.pdf

6. Donald, W.S., Yuhuan, C., Pristine, M.J., Fabiola, P.C., 2001. Quantification and variability analysis of bacterial crosscontamination rates in common food service tasks. Journal of Food Protection 64, 72-80.

7. EOS (Egyptian Organization for Standardization), 2005. Fish products breaded or in batter, EOS - 3495/2005.

8. Erickson, M.C., Liao, J.Y., Payton, A.S., 2019. Survival and internalization of Salmonella and E. coli $\mathrm{O}_{157}: \mathrm{H}_{7}$ sprayed onto different cabbage cultivars during cultivation in growth chambers. Journal of the Science of Food and Agriculture 99(7), 3530-3537.

9. FDA, 2001. Food and Drug Administration: Center for Food safety and Applied nutrition, Bacteriological Analytical Manual, S. aureus Chapter-2. www.FDA.org

10. Fredrick, S.J., Immaculate, J.K., Patterson, E.J.K., 2015. Aflatoxins Investigation on Dried Fishes of Tuticorin, South East Coast of India. Journal of Foodborne and Zoonotic Diseases 3(4), 49-62.

11. Grigoryan, K., Badalyan, G., Andriasyan, D., 2010. Prevalence of $S$. aureus in fish processing factory. Potravinarstvo Slovak Journal of Food Sciences 4(2), 25-28.

12. Guillod, C., Ghitti, F., Mainetti, C., 2019. Vibrio parahaemolyticus Induced Cellulitis and Septic Shock after a Sea Beach Holiday in a Patient with Leg Ulcers. Case Rep Dermatol 11, 94-100.

13. Hasan, N.A., Grim, C.J., Haley, B.J., 2010. Comparative genomics of clinical and environmental Vibrio mimicus. Proceedings of the National Academy of Sciences of the United States of America (PNAS) 107(49), 21134-9.

14. Hassan, H.R. 2013. Enteropathogens in fishes. Thesis, Master of Veterinary Medicine, Meat hygiene, University of Alexandria, Egypt.

15. ICMSF (International Commission of Microbiological Specification for Foods), 1996. Microorganisms in Food. Their Significance and Methods of Enumeration, $3^{\text {rd }}$ Ed., University of Toronto, Canada.

16. ISO 10273, 2017. International Organization for Standardization No. 10273: 2017. Microbiology of the food chain- Horizontal method for the detection of pathogenic $V$. parahaemolyticus.
17. Jacxsens, L., Kasuga, J., Van-der Spiegel, M., 2009. A microbial assessment scheme to measure microbial performance of food safety management systems. International Journal of Food Microbiology 34,113-125.

18. Jyhshiun, L., Kuang-Sheng, Y., Hsueh-Tao, L., 2009 Staphylococcus aureus isolated from pork and chicken carcasses in Taiwan: prevalence and antimicrobial susceptibility. Journal of Food Protection 72(3), 608-611.

19. Kok, T., Worswich, D., Gowans, E., 1996. Some serological techniques for microbial and viral infections. In Practical Medical Microbiology (Collee, J., Fraser, A., Marmion, B, Simmons, A., eds.), $14^{\text {th }}$ ed., Edinburgh, Churchill Livingstone, UK.

20. Lahmer, A.R., Williams, A.P., Jones L.D., 2017. Escherichia coli $\mathrm{O}_{157}: \mathrm{H}_{7}$ in food with health-related risks. Journal of research in health science 1 (1). DOI: 10.26739/2523-1243/-2017-1-1-1

21. MacFaddin, J.F., 2000. Biochemical tests for identification of medical bacteria. $3^{\text {rd }}$ ed., Lippincott Williams \& Wilkins, Philadelphia, PA.

22. Nichols, G.L., Little, C.L., Mithani, V., Louvois, J., 2002. Microbiological quality of take-away cooked rice and fish products sandwiches: effectiveness of food hygiene training of the management. Journal of Food Protection 62(8), 877-882.

23. Olaleye, O., Abegunde, T., 2015. Microbiological Safety Assessment of Selected Smoked Fish in Lagos Metropolis. British Microbiology Research Journal 9(3), 1-5.

24. Pinchuk, I.V., Beswick, E.J., Reyes, V.E., 2010. Staphylococcal enterotoxins. Toxins 2, 2177-2197.

25. Ramadan, M.A. 2009. Enterobacteriaceae in Fishes. Thesis, Doctor of Philosophy of Veterinary Medicine, Meat Hygiene, University of Alexandria, Egypt.

26. Shale, K., Lues, A., Venter, P., Buys, E., 2005. The distribution of Staphylococcus spp. on fish meat from fish processing plant. Journal of Food Microbiology 22(5), 433438.

27. Shimohata, T., Takahashi, A., 2010. Diarrhea induced by infection of Vibrio parahaemolyticus. The Journal of Medical Investigation 57, 179-182.

28. Soriano, J.M., Mañes, J., Soler, C., 2012. Rapid whole protein quantitation of staphylococcal enterotoxins A and B by liquid chromatography/mass spectrometry. Journal of chromatography A. 1238, 54-9.

29. Subramanian, A.T., 2007. Effect of processing on bacteria population of Cuttle fish and crab and determination of bacterial spoilage and rancidity developing on frozen storage. Journal of Food Processing and Preservation 31,13-31.

30. Toth, T., Jaroslav, A., Juraj, T., 2012. Cadmium lead and mercury contents in fishes. Journal of Microbiology, Biotechnology and Food Sciences, February Special issue 837-847.

31. Vazquez-Sanchez, D., Lopez-Cabo, M., Saa-Ibusquiza, P., 2012. Incidence and characterization of Staphylococcus aureus in fishery products marketed in Galicia (Northwest Spain). International Journal of Food Microbiology 157(2), 286-96.

32. Vigano, A., Pellissier, N., Hamad, H.J., 2007. Prevalence of E. coli, Thermo tolerant Coliforms, Salmonella spp. and Vibrio spp. in ready-to-eat foods: Pemba Island, United Republic of Tanzania. Ann.lg. 19(5), 395-403 